\title{
The blood cells count in leukocyte and leukocyte-poor platelet-concentrated plasma in patients with musculoskeletal disorders
}

\author{
Yavorovska V., Goliuk Ye., Magomedov O., Salmanova K., Saulenko K. \\ State Institute of Traumatology and Orthopedics of the National Academy of Medical Sciences of Ukraine, Kyiv, Ukraine \\ e-mail: viyavr@gmail.com
}

\section{ABSTRACT}

The cellular composition significantly affects the properties of platelet concentrates. In particular, leukocyte platelet concentrates due to the increased number of monocytes and granulocytes have increased levels of proinflammatory cytokines, which contribute to the destruction of extracellular matrix, reduce synthesis of its components and enhance inflammation in tissues.

THE PURPOSE. To determine the blood cells number in leukocyte (L-PCP) or leukocyte-poor platelet-concentrated plasma $(L P-P C P)$ and compare it with whole venous blood, plasma and platelet-poor plasma.

MATERIALS AND METHODS. 20 L-PCP and 21 LP-PCP samples were obtained by double centrifugation from the venous blood of 30 donors aged 26 to 78 with local pathology of the musculoskeletal system. In the first stage, plasma was isolated after the separation of whole blood, and in the second stage, platelets were concentrated in a small volume of platelet-poor plasma. The number of blood cells in the test samples was determined by a hematology analyzer.

RESULTS. When comparing the platelet count in L-PCP and LP-PCP, no significant difference was found in platelet number $\left(2803.2 \pm 933.8 \cdot 10^{6}\right.$ and $2260.0 \pm 943.9 \cdot 10^{6} \mathrm{cell} / \mathrm{s} / \mathrm{mL}$, respectively). The efficiency of platelet concentration from the initial volume of whole blood for the methods of obtaining LP-PCP and L-PCP did not differ significantly and was $76.5 \pm 23.4 \%$ and $83.0 \pm 24.9 \%$, respectively. Platelet count in L-PCP was 8, 13 and 239 times higher than in plasma, whole blood and platelet-poor plasma, respectively. The number of platelets in LP-PCP while exceeded their count in the same samples by 8,11 and 194 times, respectively. The leukocyte number in leukocyte-poor and leukocyte plasma with platelet concentrate was $2.5 \pm 1.2 \cdot 10^{6}$ and $5.9 \pm 1.8 \cdot 10^{6} \mathrm{cell} / \mathrm{s} / \mathrm{mL}$, respectively. However, their number in LP-PCP was almost 2 times lower than in blood and 5 times higher compared with plasma. The number of leukocytes in L-PCP was $30 \%$ higher than in the blood, and 6 times higher than in plasma. The erythrocyte number was reduced by $99 \%$ in both types of plasma with platelet concentrate compared with their count in whole blood.

CONCLUSIONS. According to the parameter of platelet isolation from whole blood, the procedures for obtaining leukocyte or leukocyte-poor platelet-concentrated plasma belong to the methods with medium efficiency. The procedure for preparing L-PCP allows to get a product with an increased relative number of leukocytes. It was possible to achieve a significant reduction in erythrocyte count for both studied products.

KEY WORDS: platelet concentrates; platelet-rich plasma; platelet-concentrated plasma

Platelet concentrates are biotechnological blood products with a platelet count greater than the normal value, which is $150-450 \cdot 10^{6} \mathrm{cell} / \mathrm{s} / \mathrm{mL}$. Platelet-rich plasma (PRP) refers to liquid platelet concentrates [17, 27, 31]. Various blood processing methods are used to produce PRP, which mainly include centrifugation [17]. Different centrifugal force and the number of centrifugations significantly affect the cell composition of the obtained PRP [34]. In particular, during double centrifugation, a larger number of platelets is sedimented [5], and to obtain leukocyte-poor PRP, one centrifugation is preferably used [26, 32]. At one centrifugation it is usually possible to increase the concentration of thrombocytes no more than in 3 times in comparison with whole blood. At present, many methods for obtaining PRP have been developed and numerous commercial kits have been designed for its preparation with different platelet isolation efficiency $[5,6,17]$. Platelet-concentrated plasma (PCP) is also obtained from PRP by platelet sedimentation and $90 \%$ plasma elimination [5].

PRP is used in many fields of medicine, such as orthopedics [31], surgery [2, 19], sports medicine [21], dentistry [4], gynecology [14], cosmetology [18] and others. The optimal concentration of platelets in 


\begin{tabular}{|c|c|c|c|c|}
\hline PATIENT & AGE & SEX & DISEASE & PCP TYPE \\
\hline 1 & 61 & Man & Gonarthrosis & L-PCP \\
\hline & & & & \\
\hline 2 & 78 & Woman & Shoulder osteoarthrosis & LP-PCP \\
\hline \multirow{2}{*}{3} & \multirow{2}{*}{74} & \multirow{2}{*}{ Woman } & \multirow{2}{*}{ Gonarthrosis } & L-PCP \\
\hline & & & & LP-PCP \\
\hline 4 & 36 & Woman & Delayed fracture healing & L-PCP \\
\hline \multirow{2}{*}{5} & \multirow{2}{*}{59} & \multirow{2}{*}{ Woman } & \multirow{2}{*}{ Gonarthrosis } & L-PCP \\
\hline & & & & LP-PCP \\
\hline 6 & 46 & Woman & $\begin{array}{l}\text { Supraspinatus tendon } \\
\text { injury }\end{array}$ & LP-PCP \\
\hline \multirow{2}{*}{7} & \multirow{2}{*}{66} & \multirow{2}{*}{ Woman } & \multirow{2}{*}{ Gonarthrosis } & L-PCP \\
\hline & & & & LP-PCP \\
\hline \multirow{2}{*}{8} & \multirow{2}{*}{63} & \multirow{2}{*}{ Man } & \multirow{2}{*}{ Meniscus tear } & L-PCP \\
\hline & & & & LP-PCP \\
\hline 9 & 57 & Woman & Coxarthrosis & L-PCP \\
\hline \multirow{2}{*}{10} & \multirow{2}{*}{56} & \multirow{2}{*}{ Woman } & \multirow{2}{*}{ Gonarthrosis } & L-PCP \\
\hline & & & & LP-PCP \\
\hline 11 & 36 & Man & $\begin{array}{l}\text { Tibial unconsolidated } \\
\text { fracture }\end{array}$ & L-PCP \\
\hline 12 & 33 & Man & Osteochondrosis & LP-PCP \\
\hline 13 & 29 & Man & Osteochondrosis & L-PCP \\
\hline 14 & 69 & Man & Ankle joint arthrosis & LP-PCP \\
\hline 15 & 48 & Man & Osteochondrosis & LP-PCP \\
\hline \multirow{2}{*}{16} & \multirow{2}{*}{62} & Woman & Gonarthrosis & L-PCP \\
\hline & & 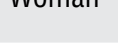 & 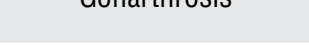 & LP-PCP \\
\hline 17 & 55 & Woman & Coxarthrosis & L-PCP \\
\hline & & & & LP-PCP \\
\hline 18 & 26 & Woman & Chondromalacia patellae & L-PCP \\
\hline & & & & LP-PCP \\
\hline 19 & 48 & Woman & Coxarthrosis & L-PCP \\
\hline & & & & LP-PCP \\
\hline 20 & 60 & Woman & Meniscus tear & LP-PCP \\
\hline 21 & 52 & Woman & Gonarthrocis & L-PCP \\
\hline 21 & $J 6$ & 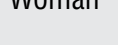 & 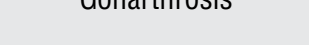 & LP-PCP \\
\hline 22 & 57 & Woman & Coxarthrosis & L-PCP \\
\hline 23 & 48 & Woman & Coxarthrosis & L-PCP \\
\hline 24 & 54 & Woman & $\begin{array}{l}\text { Supraspinatus } \\
\text { tendinopathy }\end{array}$ & L-PCP \\
\hline 25 & 54 & Man & Coxarthrosis & L-PCP \\
\hline 26 & 58 & Man & Gonarthrosis & LP-PCP \\
\hline 27 & 49 & Woman & Meniscus tear & LP-PCP \\
\hline 28 & 64 & Woman & Coxarthrosis & L-PCP \\
\hline 29 & 28 & Man & Meniscus tear & L-PCP \\
\hline 30 & 49 & Woman & Meniscus tear & LP-PCP \\
\hline
\end{tabular}

Note: L-PCP - leukocyte platelet-concentrated plasma, LP-PCP - leukocyte-poor platelet-concentrated plasma.
PRP to ensure a therapeutic effect is the subject of scientific discussion and numerous studies, which results are ambiguous. It is believed that for PRP the platelet count should be at least $1 \cdot 10^{9}$ cells $/ \mathrm{mL}$ to effectively ensure tissue repair $[14,25]$. Thus, in tenocyte culture, it was demonstrated that the concentration of platelets from $5 \cdot 10^{5}$ to $1 \cdot 10^{6}$ platelets $/ \mu \mathrm{L}$ in PRP stimulated cell proliferation and migration, as well as collagen synthesis [25]. While the number of platelets from 1 to $1.5 \cdot 10^{6}$ platelets/ $\mathrm{LL}$ enhances the proliferation of endothelial cells and fibroblasts [26, 27]. On the other hand, high platelet concentrations can lead to inhibition of cell metabolism and reduction of collagen synthesis [8, 25]. However, in the elderly, due to the increase in the concentration of platelets in the PRP, cell proliferation increases [7].

Platelet concentrates also contain other types of circulating blood cells. The number of leukocytes is one of the most important indicators for such products, as they can significantly affect its properties [37, 38]. According to their content, platelet concentrates are divided into leukocyte and leukocyte-poor ones [17]. Leukocyte platelet concentrates are characterized by higher leukocyte count compared to whole blood, while in leukocyte-poor ones their count is lower [28, 46, 50]. Leukocyte platelet concentrates contain significant number of granulocytes and monocytes, which produce proinflammatory cytokines: tumor necrosis factor a (TNFa), interleukins $1 \beta, 6$ and 8 . These cytokines induce the expression of genes that promote the destruction of the extracellular matrix and enhance inflammation, including genes of proinflammatory interleukins, prostaglandins, inducible NO-synthase, cyclooxygenase 2 and metalloproteinases $[40,48,49]$. Despite a number of possible negative effects, leukocyte platelet concentrates can promote healing and regulate inflammation, in particular enhance the synthesis of growth factors and have a pronounced antimicrobial effect, so they should not be completely excluded from clinical application [17]. There is also evidence that leukocyte PRP stimulates the proliferation of chondrocytes, tendocytes and myocytes, and, therefore, leukocyte platelet concentrates can be used to treat cartilage disorders, including osteoarthritis [1, 21, 30].

While studying the cellular components of platelet concentrates, insufficient attention is paid to the number of erythrocytes [16]. Some studies have shown that the number of red blood cells in PRP is minor because their count is reduced by $90 \%$ compared with whole blood $[9,40]$. However, erythrocytes can be harmful to cells due to increased oxidative damage and affect the synthesis of extracellular matrix [23, 24].

The PURPOSE of the study was to compare the blood cells count in leukocyte (L-PCP) and leukocyte-poor platelet-concentrated plasma (LP-PCP), as well as to compare them with venous blood, plasma and platelet-poor plasma.

\section{MATERIALS AND METHODS}

The material for the study was blood, plasma and autologous biotechnological products of blood of 30 patients with various diseases and injuries of the musculoskeletal system. There were 20 women aged 26 to 78 years (mean age $55 \pm 12$ years) and 10 men aged 28-69 years (mean age $48 \pm 14$ years).

The venous blood was obtained fasting by the informed consent. The 20 leukocyte and 21 leukocyte-poor platelet concentrates were prepared. Platelet-concentrated plasma products were processed by Araki technique [5] with some modifications. 41 control samples of venous blood and plasma were also obtained.

Thrombocytopenia or anaemia was not diagnosed in the study participants. They also had local pathology of the musculoskeletal system without exacerbation of concomitant diseases, so this group can be considered homogeneous. One week before blood sampling, patients were discontinued non-steroidal anti-inflammatory drugs, prescribed a spe- 

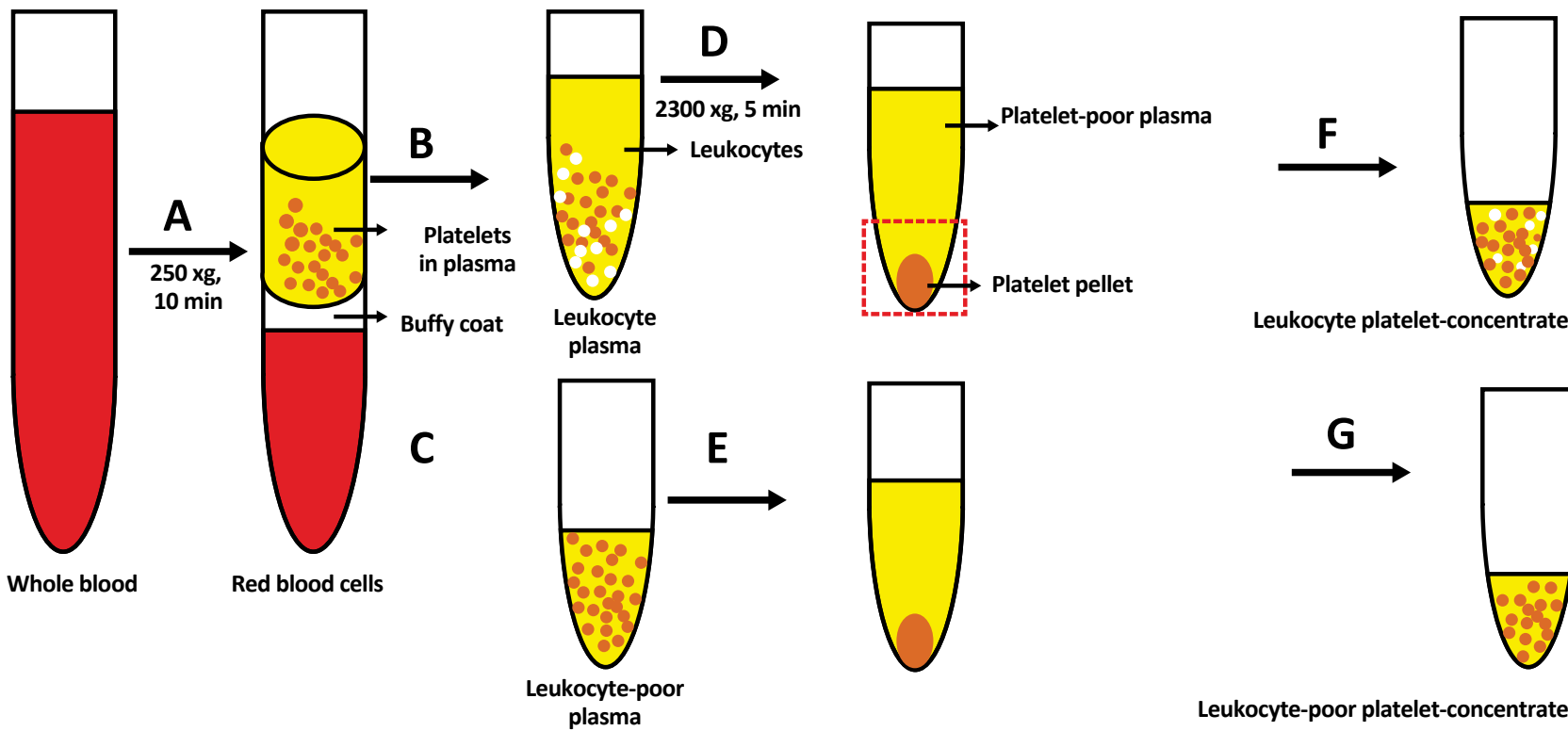

Leukocyte platelet-concentrated plasma
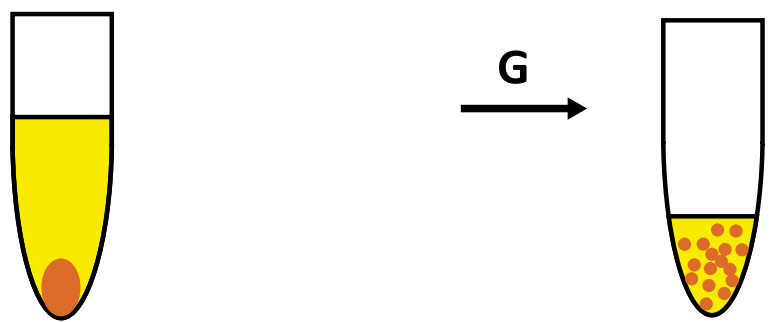

Leukocyte-poor platelet-concentrated plasma

Fig. 1. The scheme for obtaining leukocyte and leukocyte-poor platelet-concentrated plasma from whole blood (according to Liu F, 2019)
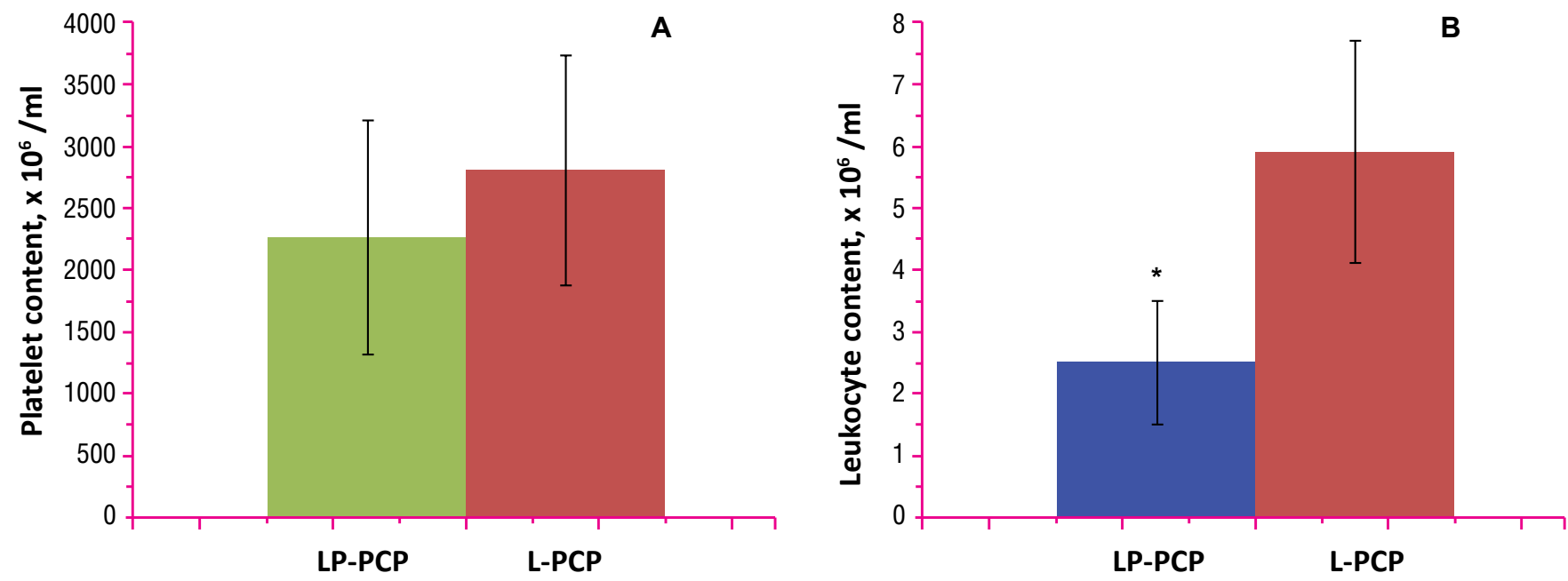

A Fig. 2. Platelet number in the samples of LP-PCP and L-PCP in patients with musculoskeletal disorders, $M \pm m(n=21)$. Note: * $-p \leq 0.05$ compared with L-PCP group.

cial diet (exclusion of fatty, fried and spicy foods, total daily intake up to 3 liters, no coffee) and regimen (prohibition of smoking and drinking alcohol). The distribution of patients by types of blood products and by diseases is presented in Table $\mathbf{1 .}$

To prepare the product of leukocyte platelet-concentrated plasma, $50 \mathrm{~mL}$ of venous blood was collected in $10 \mathrm{~mL}$ Vacutainer $^{\mathrm{TM}}$ Blood Collection Tubes with Acid Citrate Dextrose (BD, USA). After sampling, venous blood was centrifuged at $250 \mathrm{xg}$ for 10 min to separate plasma and blood cells using a CM-3 centrifuge (MICROmed, China). After centrifugation, the blood plasma was gently agitated to increase the concentration of leukocytes, as white blood cells rise into the plasma from the upper buffy coat layer. After that, $25-30 \mathrm{~mL}$ blood plasma with a high number of leukocytes was transferred into new $10 \mathrm{~mL}$ tubes and centrifuged at $2300 \mathrm{xg}$ for 5 minutes. The resulting platelet pellet was resuspended in $3 \mathrm{~mL}$ of plateletpoor plasma, which remained when most platelets were removed after the second centrifugation. Since $3 \mathrm{~mL}$ of plasma is an optimal volume for injection into the patient's joint to reduce pain from excess injected fluid, it was chosen for the study. Most volume (about $90 \%$ ) of platelet-poor plasma was removed.

To prepare the product of leukocyte-poor platelet-concentrated plas$\mathrm{ma}, 50 \mathrm{~mL}$ of venous blood was collected in $10 \mathrm{~mL}$ Vacutainer ${ }^{\mathrm{TM}}$ Blood Collection Tubes with Acid Citrate Dextrose (BD Vacutainer, USA). Blood plasma after the first centrifugation at $250 \mathrm{xg}$ for 10 min was collected in new $10 \mathrm{~mL}$ vials without agitation to reduce the number of leukocytes. After that, the collected plasma was centrifuged at $2300 \mathrm{xg}$ for 5 minutes. The resulting cell pellet was also resuspended in $3 \mathrm{~mL}$ of platelet-poor plasma. Most volume of the platelet-poor plasma was removed. The general scheme for obtaining PCP is shown in Fig. 1.

To study the cell count in whole blood, plasma and platelet-poor plasma, samples of about $1.5 \mathrm{~mL}$ were taken. Platelet-concentrated plasma was diluted 2 times with Hartmann's solution (Infusion, Ukraine) prior to cells number count. Blood, plasma, L-PCP and LP-PCP samples were analyzed on a Celltac Alpha hematology analyzer (Nihon Kohden, Japan). 


\begin{tabular}{|c|c|c|c|c|c|}
\hline CELL TYPE & WHOLE BLOOD & PLASMA & LP-PCP & $\begin{array}{l}\text { PLATELET- } \\
\text { POOR PLASMA }\end{array}$ & $\begin{array}{l}\text { Table } 2 \text {. The number of different cell } \\
\text { types in blood, plasma, leukocyte-poor }\end{array}$ \\
\hline White blood cells, $10^{6}$ cells $/ \mathrm{mL}$ & $4.5 \pm 1.2$ & $0.5 \pm 0.2^{*}$ & $2.5 \pm 1.1^{*}$ & $0.1 \pm 0.0^{*}$ & $\begin{array}{l}\text { platelet-concentrated plasma (LP-PCP) } \\
\text { and platelet-poor plasma: } n=21\end{array}$ \\
\hline Red blood cells, $10^{6}$ cells $/ \mathrm{mL}$ & $4040.0 \pm 385.3$ & $13.0 \pm 5.71^{*}$ & $43.0 \pm 16.7^{\star}$ & $2.63 \pm 4.5^{\star}$ & Note: * $-p \leq 0.05$ compared with \\
\hline Platelets, $10^{6}$ cells $/ \mathrm{mL}$ & $191.0 \pm 42.1$ & $279.05 \pm 75.6^{\star}$ & $2260.0 \pm 943.9^{*}$ & $11.9 \pm 8.5^{\star}$ & whole blood. \\
\hline
\end{tabular}

\begin{tabular}{|c|c|c|c|c|c|}
\hline CELL TYPE & WHOLE BLOOD & PLASMA & L-PCP & $\begin{array}{l}\text { PLATELET- } \\
\text { POOR PLASMA }\end{array}$ & $\begin{array}{l}\text { Table 3. The number of different cell } \\
\text { types in blood, plasma, leukocyte }\end{array}$ \\
\hline White blood cells, $10^{6}$ cells $/ \mathrm{mL}$ & $4.7 \pm 0.7$ & $1.0 \pm 0.3^{*}$ & $5.9 \pm 1.8^{*}$ & $0.095 \pm 0.0$ & $\begin{array}{l}\text { platelet-concentrated plasma (L-PCP) } \\
\text { and platelet-poor plasma }(n=20) .\end{array}$ \\
\hline Red blood cells, $10^{6}$ cells $/ \mathrm{mL}$ & $4012.0 \pm 417.6$ & $15.2 \pm 6.0^{*}$ & $50.0 \pm 2.0^{*}$ & $1.42 \pm 3.6^{\star}$ & Note: ${ }^{*}-p \leq 0.05$ compared with \\
\hline Platelets, $10^{6}$ cells $/ \mathrm{mL}$ & $208.8 \pm 36.7$ & $336.8 \pm 70.4^{\star}$ & $2803.0 \pm 933.8^{*}$ & $11.71 \pm 7.6^{\star}$ & whole blood. \\
\hline
\end{tabular}

Numerical characteristics of the parameters were calculated by the methods of descriptive statistics and are presented in the form of average value and standard deviation $\mathrm{M} \pm \mathrm{m}$. Student's t-test with Bonferroni correction was used as a criterion for the reliability of differences between the compared groups. P-values of less than 0.05 were regarded as statistically significant. Statistical analysis of data was performed using MS Excel software (Microsoft, USA).

\section{RESULTS AND DISCUSSION}

The study of peripheral blood cell count of 30 patients found that the number of leukocytes, erythrocytes and platelets was $4.6 \pm 1 \cdot 10^{6} \mathrm{cells} / \mathrm{mL}$, $4014.0 \pm 397.7 \cdot 10^{9} \mathrm{cell} \mathrm{s} / \mathrm{mL}$ and $196.6 \pm 43 \cdot 10^{6} \mathrm{cell} / \mathrm{sL}$, respectively.

The number of platelets in LP-PCP and L-PCP was $2260.0 \pm 943.9 \cdot 10^{6}$ and $2803.2 \pm 933.8 \cdot 10^{6} \mathrm{cell} / \mathrm{sL}$, respectively (Fig. 2 A). Therefore, no significant difference was found between the platelet count in these biotechnological products, which coincides with the data of some studies on platelet-rich plasma [36, 40, 43, 47]. However, some studies have shown that the number of platelets in leukocyte-poor platelet concentrates is significantly lower than in leukocyte-containing ones [6, 39]. Since many methods of LP-PCP preparation use single centrifugation, it significantly reduces the number of platelets compared with L-PCP $[6,34,38]$.

The efficiency of platelet isolation for both methods of obtaining concentrates is also comparable and is $76.5 \pm 23.4 \%$ and $83.0 \pm 24.9 \%$ for LP-PCP and L-PCP, respectively. Therefore, the protocols used for obtaining LP-PCP and L-PCP belong to the methods with average efficiency of platelet concentration from whole blood according to DEPA classification of such cellular products proposed by Magalon J. [28].

It was shown that the number of platelets in LP-PCP was increased compared with plasma, whole blood and platelet-poor plasma in 8,11 and 194 times, respectively (Table 2). While the number of platelets in L-PCP exceeded their count in leukocyte-containing plasma, whole blood and platelet-poor plasma in 8,13 and 239 times, respectively (Table 3). There is a lack of literature data on the influence of many factors, such as age and concomitant pathology, on the platelets number in cell concentrate products. However, Weibrich G. [44] showed that age has almost no effect on platelet counts in PRP. In addition, Pauly S. [38], who used the blood of patients with tendopathies to prepare PRP, are comparable to data from another study [35] that used blood from healthy individuals. Both studies used the same commercial blood processing technique.

Since the number of platelets in the whole blood of healthy adults varies in a relatively wide range of $150-450 \cdot 10^{6} \mathrm{cell} / \mathrm{s} / \mathrm{mL}$, this factor must be taken into account in the production of all types of platelet concentrates [16]. In addition, in some diseases, including immune thrombocytopenia and chronic leukocyte leukemia, the platelet number in the blood is reduced to $100 \cdot 10^{6}$ cells $/ \mathrm{mL}$ and less $[41,42]$. When studying the

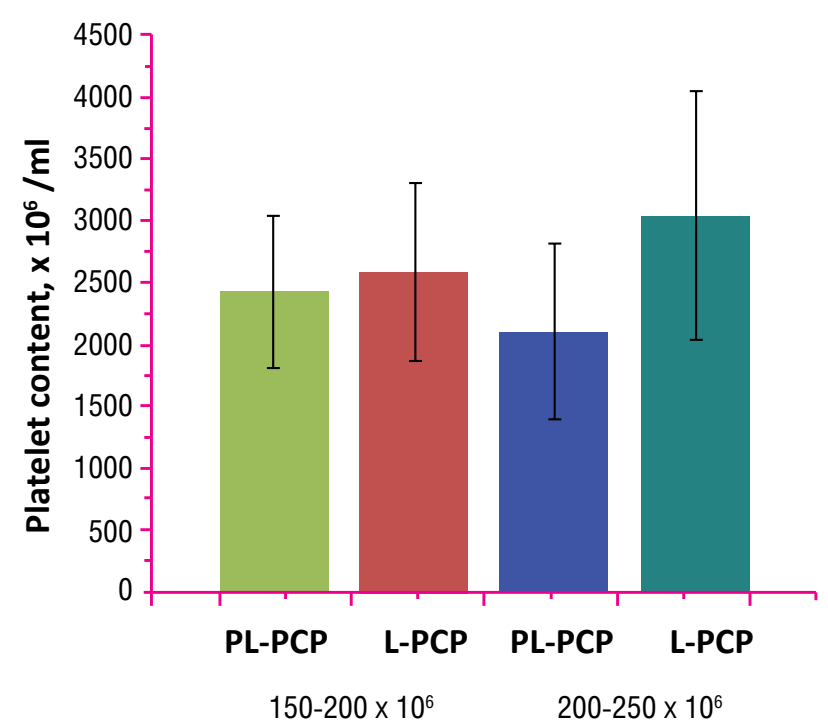

Platelet count of whole blood, $\mathrm{ml}$

Fig. 3. Platelet count in L-PCP and LP-PCP from patients with different number of platelets in whole blood $(\mathrm{M} \pm \mathrm{m} ; \mathrm{n}=7-10)$.

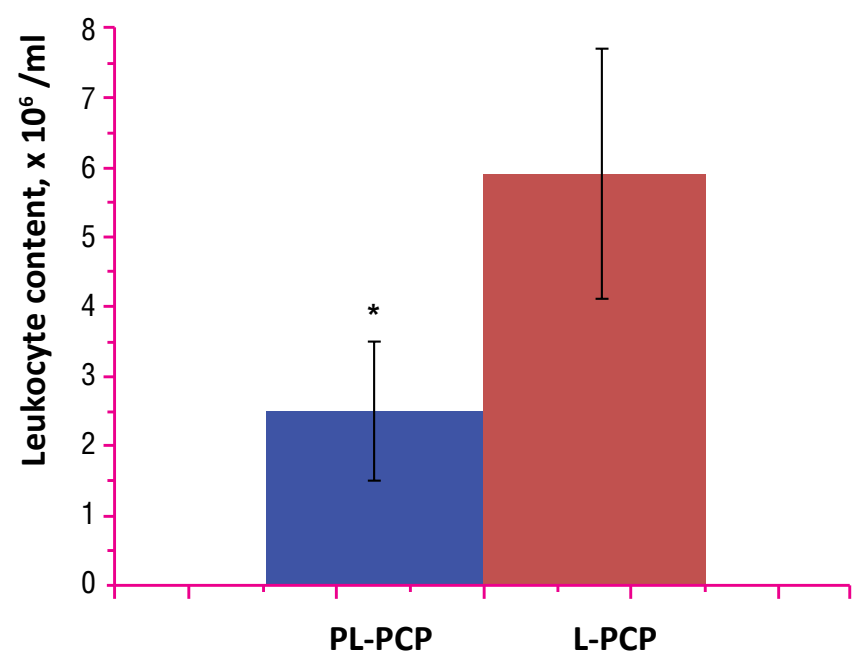

Fig. 4. The number of leukocytes in the samples of LP-PCP and L-PCP in patients with musculoskeletal disorders, $M \pm m(n=21)$.

Note: ${ }^{*}-p \leq 0.05$ compared with the group L-PCP. 
correlation between the platelets count in whole blood and in the prepared concentrates, the products were divided into two groups according to the number of platelets in the processed blood. It was shown that in L-PCP made from the individuals with the number of platelets in whole blood $150-200 \cdot 10^{6}$ cells $/ \mathrm{mL}$ and $200-250 \cdot 10^{6}$ cells $/ \mathrm{mL}$, the platelet count was $2586 \pm 715$ and $3043 \pm 999$ cells $/ \mathrm{mL}$, respectively. While in LP-PCP the number of thrombocytes for the same comparison groups was $2423 \pm 613$ and $2107 \pm 705$ cells/mL, respectively (Fig. 3). Therefore, there was no significant difference in platelet count in PCP from patients with increased (more than $200 \cdot 10^{6}$ cells $/ \mathrm{mL}$ ) and reduced (up to $200 \cdot 10^{6}$ cells $/ \mathrm{mL}$ ) platelet number in whole blood. An increased number of platelets in the blood above $300 \cdot 10^{6}$ cells $/ \mathrm{mL}$ may have a more significant effect on their final count in PCP. However, there were not enough people with high platelet number in our group to study this.

Some authors have shown that the platelets count correlates with the level of growth factors in platelet concentrates $[5,19]$, in particular, transforming growth factor $\beta 1$, platelet growth factor-BB, hepatocyte growth factor and epidermal growth factor [22, 40].

The number of leukocytes in LP-PCP was reduced by 2 times compared with L-PCP (Fig. 4). It was also 2 times lower than in blood, but 5 times higher than in plasma. This correlates with the data of some other studies [35]. The number of leukocytes in LP-PCP and L-PCP was 2.5 $\pm 1.2 \cdot 10^{6}$ and $5.9 \pm 1.8 \cdot 10^{6} \mathrm{cells} / \mathrm{mL}$, respectively. The leukocytes count in L-PCP was $30 \%$ higher than in the blood, and 6 times higher than in plasma. However, the composition and number of different cell types in platelet concentrates are significantly influenced by different initial conditions in the product processing, including the volume of collected blood, the centrifugal force at blood separation, the number of centrifugations, etc.

It is known that L-PCP products have increased level of pro-inflammatory interleukins. In particular, in the culture of synovial membrane fibroblasts, it was shown that L-PCP enhanced the synthesis of proin- flammatory IL-1 $\beta$ and IL-8 $[6,38,45,46]$. In addition, it was shown that leukocyte-poor platelet-rich plasma significantly enhanced the proliferation of human osteocytes, myocytes and ligament cells [32]. While leukocytes-containing platelet-rich plasma inhibited the proliferation of tendocytes and mesenchymal stem cells, as well as cell differentiation into cartilage and bone tissue $[45,48,50,51]$. In addition, leukocyte platelet concentrates can reduce the synthesis of extracellular matrix molecules in tissues. In particular, in the cartilage tissue under the influence of $\mathrm{IL}-1 \beta$ and TNFa, the synthesis of the main components of the extracellular matrix (aggrecans and type II collagen) decreases $[9,11]$. This can be explained by the production of pro-inflammatory cytokines in leukocyte platelet concentrates, which contribute to catabolic processes in tissues [6]. Despite these negative effects, the use of L-PCP can promote healing processes, in particular to enhance the synthesis of growth factors. In addition, they have a pronounced antimicrobial effect, so they should not be completely excluded from clinical application [17]. Moreover, in clinics there is a lack of data on the negative effects of leukocyte platelet concentrates compared to leukocyte-poor ones [11, 34]. In addition, some clinical studies have shown that platelet-rich plasma with leukocytes did not increase the level of pro-inflammatory interleukins in the synovial membrane of the joint at the treatment of gonarthrosis [29].

The number of erythrocytes was reduced by $99 \%$ in LP-PCP and L-PCP compared with their count in the whole blood. However, red blood cells number in LP-PCP was 3 times higher than in plasma and 18 times higher than in platelet-poor plasma. The number of erythrocytes in L-PCP was 4 and 40 times higher than in native plasma and platelet-poor plasma, respectively. However, erythrocytes can be harmful to cells and tissues [9, 23, 24]. In particular, it has been shown that red blood cells decrease the viability of synoviocytes [9], as well as reduce the synthesis of cartilage proteoglycans $[23,24]$. It is assumed that the mechanism of adverse effects of red blood cells is associated with increased oxidative damage caused by iron in hemoglobin [23].

\section{CONCLUSION}

Thus, the efficiency of platelet isolation in the procedures of obtaining LP-PCP and L-PCP in patients with musculoskeletal disorder is comparable and they can be attributed to methods with average efficiency of the concentration of platelets from whole blood. There was no significant difference in platelet count in manufactured products from patients with high and low primary platelet count in whole blood. The processing of L-PCP allows to obtain a product with a relative number of leukocytes, which is $30 \%$ higher than in whole blood, and almost twice as much as in LP-PCP. For both studied products it was possible to achieve a significant reduction in the number of erythrocytes compared to its count in the whole blood.

The justification for a differentiated approach to the choice of biotechnological product depending on the pathology of the musculoskeletal system is considered to be the prospect of further research in the clinical application of different types of autologous platelet concentrates.

\section{REFERENCES}

1. Akeda K, An HS, Okuma M, et al. Platelet-rich plasma stimulates porcine articular chondrocyte proliferation and matrix biosynthesis. Osteoarthr Cartilage. 2006; 12:1272-1280. DOl:10.1016/j.joca.2006.05.008.

2. Alsousou J, Thompson M, Hulley P. The biology of platelet-rich plasma and its application in trauma and orthopaedic surgery. J Bone Joint Surg Br. 2009; 91(8):98796. DOI:10.1302/0301-620X.91B8.22546.

3. Anitua E, Andia I, Ardanza B. Autologous platelets as a source of proteins for healing and tissue regeneration. Thromb Haemost. 2004; 91:4-15. DOI:10.1160/TH0307-0440.

4. Anitua $E$, Orive G. Clinical outcome of immediately loaded dental implants bioactivated with plasma rich in growth factors: a 5 -year retrospective study. J Periodontol. 2008; 79(7):1168-1176. DOl:10.1902/jop.2010.090637.

5. Araki J, Jona $M$, Eto $\mathrm{H}$. Optimized preparation method of platelet-concentrated plasma and noncoagulating platelet-derived factor concentrates: maximization of platelet concentration and removal of fibrinogen. Tissue Eng Part C Methods 2012; 18(3):176-85. DOl:10.1089/ten.TEC.2011.0308.

6. Assirelli E, Filardo G. Effect of two different preparations of platelet-rich plasma on synoviocytes. Knee Surg Sport Tra. 2015; 23(9):2690-2703. D0I:10.1007/s00167014-3113-3.

7. Berger DR, Centeno CJ, Steinmetz NJ. Platelet lysates from aged donors promote human tenocyte proliferation and migration in a concentration-dependent manner. Bone Joint Res. 2019; 8(1):32-40. DOI:10.1302/2046-3758.81.BJR-2018-0164.R1. 
8. Boswell SG, Schnabel LV, Mohammed HO. Increasing platelet concentrations in leukocyte-reduced platelet-rich plasma decrease collagen synthesis in tendons. Am J Sports Med. 2014; 42(1):42-9. DOI:10.1177/0363546513507566.

9. Braun HJ, Kim HJ, Chu CR. The effect of platelet-rich plasma formulations and blood products on human synoviocytes: implications for intra-articular injury and therapy. Am J Sports Med. 2014; 42(5):1204-10. DOl:10.1177/0363546514525593.

10. Campbell KA, Minashima T. Annexin A6 interacts with p65 and stimulates NF-KB activity and catabolic events in articular chondrocytes. Arthritis Rheum. 2013; 65(12):3120-9. DOI:10.1002/art.38182.

11. Centeno CJ, Pastoriza SM. Past, current and future interventional orthobiologics techniques and how they relate to regenerative rehabilitation: a clinical commentary. Int J Sports Phys Ther. 2020; 15(2):301-325.

12. Chaly YV, Selvan RS, Fegeding KV. Expression of II-8 gene in human monocytes and lymphocytes: differential regulation by TNF and IL-1. Cytokine. 2000; 12:636-643. DOl:10.1006/cyto.1999.0664.

13. Crane D, Everts $P$. Platelet rich plasma (PRP) matrix grafts. Pract PAIN Manag. 2008; 8(1):1-10.

14. Dawood AS, Salem HA. Current clinical applications of platelet-rich plasma in various gynecological disorders: An appraisal of theory and practice. Clin Exp Reprod Med. 2018; 45(2):67-74. DOI:10.5653/cerm.2018.45.2.67.

15. de Melo BAG, Martins Shimojo AA. Distribution, recovery and concentration of platelets and leukocytes in L-PRP prepared by centrifugation. Colloid Surf B. 2018; 161:288-295. DOI:10.1016/j.colsurfb.2017.10.046.

16. Dhillon RS, Schwarz EM, Maloney MD. Platelet-rich plasma therapy - future or trend? Arthritis Res Ther. 2012; 14(4):219-229. D0I: $10.1186 /$ ar3914.

17. Dohan Ehrenfest DM, Rasmusson L. Classification of platelet concentrates (Platelet-Rich Plasma-PRP, Platelet-Rich Fibrin-PRF) for topical and infiltrative use in orthopedic and sports medicine: current consensus, clinical implications and perspectives. M.L.T.J. 2014; 4(1):3-9.

18. Elghblawi E. Platelet-rich plasma, the ultimate secret for youthful skin elixir and hair growth triggering. J Cosmet Dermatol. 2018; 17(3):423-430. D0l:10.1111/ jocd.12404.

19. Eppley BL, Pietrzak WS, Blanton M. Platelet-rich plasma: a review of biology and applications in plastic surgery. Plast Reconstr Surg. 2006; 118(6):147-159. DOl:10.1097/01.prs.0000239606.92676.cf.

20. Eppley BL, Woodell JE, Higgins J. Platelet quantification and growth factor analysis from platelet-rich plasma: implications for wound healing. Plast Reconstr Surg. 2004; 114(6):1502-1508. D0l:10.1097/01.prs.0000138251.07040.51.

21. Fortier $L A$, Hackett $C H$, Cole BJ. The effects of platelet-rich plasma on cartilage: basic science and clinical application. Oper Tech Sports Med. 2011; 19(3):154-159.

22. Dahlgren LA, Mohammed HO, Nixon AJ. Temporal expression of growth factors and matrix molecules in healing tendon lesions. J Orthop Res. 2005; 23(1):84. doi. org/10.1016/j.orthres.2004.05.007.

23. Hooiveld MJ, Roosendaal G, van den Berg HM. Hemoglobin-derived iron-dependent hydroxyl radical formation in blood-induced joint damage: an in vitro study. Rheumatology. 2003; 42(6):784-90. D0l:10.1093/rheumatology/keg220.

24. Hooiveld MJ, Roosendaal G. Blood-induced joint damage: Iong-term effects in vitro and in vivo. Arthritis Rheum. 2003; 48(2):396-403. D0l:10.1002/art.10769.

25. Giusti I, D'Ascenzo S, Mancò A, Di Stefano G, Di Francesco M, Rughetti A, et al. Platelet concentration in platelet-rich plasma affects tenocyte behavior in vitro. BioMed Res Int. 2014; 2014:630870.

26. Giusti I, Rughetti A, D'Ascenzo S. The effects of plateletgel-released supernatant on human fibroblasts. Wound Repair and Regeneration. 2013; 21(2):300-308. DOl:10.1111/wrr.12025.

27. Giusti I, Rughetti A, D'Ascenzo S. Identification of an optimal concentration of platelet gel for promoting angiogenesis in human endothelial cells. Transfusion. 2009; 49(4):771-8. DOI: 10.1111/j.1537-2995.2008.02033.x

28. Magalon J, Chateau AL. DEPA classification: a proposal for standardising PRP use and a retrospective application of available devices. BMJ Open Sport Exerc Med. 2016; 2(1):1-5. DOl:10.1136/bmjsem-2015-000060.

29. Mariani E, Canella V, Cattini L. Leukocyte platelet-rich plasma injections do not up-modulate intra-articular pro-inflammatory cytokines in the osteoarthritic knee. PLoS One. 2016; 11(6):0156137. D0l:10.1371/journal.pone.0156137.

30. Masuki $H$, Okudera $T$, Watanebe $T$. Growth factor and pro-inflammatory cytokine contents in platelet-rich plasma (PRP), plasma rich in growth factors (PRGF), advanced platelet-rich fibrin (A-PRF), and concentrated growth factors (CGF). Int J Implant Dent. 2016; 2(1):19. D0l:10.1186/s40729-016-0052-4.

31. Marx RE: Platelet-rich plasma (PRP): what is PRP and what is not PRP? Implant Dent. 2001; 10:225-228.21. D0l:10.1097/00008505-200110000-00002.

32. Mazzocca AD, McCarthy MB. The positive effectsof different plateletrich plasma methods on human muscle, bone, and tendon cells. Am J Sports Med. 2012; 40(8):1742-9. DOI:10.1177/0363546512452713.

33. Melo BAG, Luzo ÂCM. Centrifugation conditions in the L-PRP preparation affect soluble factors release and mesenchymal stem cell proliferation in fibrin nanofibers molecules. 2019; 24(15):2729. DOl:10.3390/molecules24152729.

34. Moatshe G, Morris ER. Biological treatment of the knee with platelet-rich plasma or bone marrow aspirate concentrates. Acta Orthop. 2017; 88(6):670-674. D0I:10.1 080/17453674.2017.1368899.

35. Noh KC, Liu XN, Zhuan Z, Leukocyte-poor platelet-rich plasma-derived growth factors enhance human fibroblast proliferation in vitro. Clin Orthop Surg. 2018; 10(2):240-247. DOl:10.4055/cios.2018.10.2.240.

36. Rohman G, Langueh C. The Use of platelet-rich plasma to promote cell recruitment into low-molecular-weight. Polymers. 2019. D0I: 10.3390/polym11061016.

37. Paterson KL, Hunter DJ, Metcalf BR. Efficacy of intra-articular1injections of platelet-rich plasma as a symptom- and disease-modifying treatment for knee osteoarthritis - the restore trial protocol. BMC Musculoskelet Disord. 2018; 19(1):272. DOl.org/10.1186/s12891-018-2205-5.

38. Pauly S. The effect of autologous platelet rich plasma on tenocytes of the human rotator cuff BMC Musculoskelet Disord. 2018; 19(1):422. D0l:10.1186/s12891-0182339-5.

39. Pochini AC, Antonioli E, Bucci DZ. Analysis of cytokine profile and growth factors in platelet-rich plasma obtained by open systems and commercial columns. Einstein. 2016; 14(3):391-397. DOl:10.1590/S1679-45082016A03548.

40. Taniguchi Y, Yoshioka T. Growth factor levels in leukocyte-poor platelet-rich plasma and correlations with donor age, gender, and platelets in the Japanese population. J Exp Orthop. 2019; 4. DOl:10.1186/s40634-019-0175-7.

41. Samson M, Fraser W, Lebowitz D. Treatments for primary immune thrombocytopenia: A Review. Cureus. 2019, 11(10):5849. D0I:10.7759/cureus.5849.

42. Vitale C. Autoimmune Complications in chronic lymphocytic leukemia in the era of targeted drugs cancers (Basel). 2020; 12(2):282. D01:10.3390/cancers12020282.

43. Wang SZ, Fan WM, Jia J. Is exclusion of leukocytes from platelet-rich plasma (PRP) a better choice for early intervertebral disc regeneration? Stem Cell Res Ther. 2018; 9(1):199. DOl:10.1186/s13287-018-0937-7. 
44. Weibrich G, Kleis WK, Kunz-Kostomanolakis M. Correlation of platelet concentration in platelet-rich plasma to the extraction method, age, sex, and platelet count of the donor. Int J Oral Maxillofac Implants. 2001; 16(5):693-9.

45. Xu X, Zheng L, Yuan Q, Zhen G, Crane JL, Zhou X, Cao X. Transforming growth factor- $\beta$ in stem cells and tissue homeostasis. Bone Res. 2018; 6. DOI: 10.1038/ s41413-017-0005-4.

46. Xu Z, Yin W, Zhang Y. Comparative evaluation of leukocyte- and platelet-rich plasma and pure platelet-rich plasma for cartilage regeneration. Sci Rep. 2017 ; 7:43301. DOI:10.1038/srep43301.

47. Yuan T, Guo SC, Han P, Zhang CQ, Zeng BF. Applications of leukocyte- and platelet-rich plasma (L-PRP) in trauma surgery. Curr Pharm Biotechnol. 2012; 13(7):117384. DOI:10.2174/ 138920112800624445.

48. Yin W, Xin Q, Zhang Y. Advantages of pure platelet-rich plasma compared with leukocyte- and platelet-rich plasma in promoting repair of bone defects. J Transl Med. 2016; 14:73. DOI:10.1186/s12967-016-0825-9.

49. Yin WJ, Xu HT, Sheng JG. Advantages of pure platelet-rich plasma compared with leukocyte- and platelet-rich plasma in treating rabbit knee osteoarthritis. Med Sci Monit. 2016; 22:1280-90. DOI:10.12659/msm.898218.

50. Zhou $Y$, Zhang J, Wu $\mathrm{H}$. The differential effects of leukocyte-containing and pure platelet-rich plasma (PRP) on tendon stem/progenitor cells - implications of PRP application for the clinical treatment of tendon injuries. Stem Cell Res Ther. 2015; 6:173. DOl:10.1186/s13287-015-0172-4.

51. Zhang L, Chen S, Chang P. Harmful effects of leukocyte platelet-rich plasma on rabbit tendon stem cells in vitro. Am J Sports Med. 2016 ; 44(8):1941-51. DOl: $10.1177 / 0363546516644718$

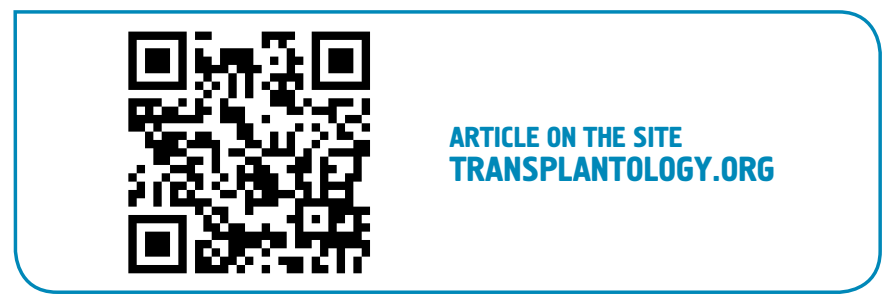

The authors declared no potential conflicts of interest with respect to the research, authorship, and/or publication of this article. 